\title{
UM ESTUDO SOBRE A VERTICALIZAÇÃO E A TERCEIRIZAÇÃO DOS PROCESSOS DE LEITURA E DE ENTREGA DE FATURAS DE UMA DISTRIBUIDORA DE ENERGIA ELÉTRICA
}

\section{A STUDY ABOUT THE VERTICAL INTEGRATION AND THE OUTSOURCING OF METER READING AND DELIVERY PROCESS OF ELECTRICAL BILLS IN AN ELECTRICITY DISTRIBUTOR}

\author{
Gabriel Sperandio Milan ${ }^{1}$; Patrícia Fritzen Theisen ${ }^{2}$ \\ ${ }^{1}$ Universidade de Caxias do Sul - UCS - Caxias do Sul - Brasil \\ gsmilan@ucs.br \\ ${ }^{2}$ Universidade de Caxias do Sul - UCS - Caxias do Sul - Brasil \\ patitheisen@gmail.com
}

\begin{abstract}
Resumo
O trabalho apresenta um estudo de caso sobre a verticalização dos processos de leitura e entrega de faturas em uma distribuidora de energia elétrica da região Sul do Brasil. O trabalho tem por objetivo descrever a migração dos processos analisados, do modelo terceirizado para verticalizado. $O$ estudo também contempla a análise dos riscos e benefícios de ambos os modelos. Outro aspecto abordado é a demonstração dos resultados obtidos na empresa em análise, que foram extremamente significativos desde a sua implantação. A verticalização trouxe uma diminuição no número de reclamações de faturas não entregues, redução do número de solicitações de segundas vias, melhora na qualidade do faturamento, redução de custos e ainda uma importante melhoria nos índices de satisfação dos clientes com relação aos serviços de leitura $e$ entrega de faturas. Faz-se a relação entre os resultados alcançados pela organização com o referencial teórico existente sobre o assunto, buscando demonstrar que nem sempre a terceirização é a melhor alternativa.
\end{abstract}

Palavras-chave: processos em serviços; verticalização de processos; terceirização.

\section{Introdução}

A RGE - Rio Grande Energia S/A. é a distribuidora de energia elétrica da região nortenordeste do Estado do Rio Grande do Sul (RS). Oriunda de um processo de privatização de serviços públicos realizado em outubro de 1997, a RGE atende 262 municípios, o que representa 51\% do total de municípios do RS, possuindo, de acordo com dados divulgados em dezembro de 2008, 1.198.560 unidades consumidoras. A área de cobertura da empresa divide-se em duas regiões: a Centro, com sede em Passo Fundo e a Leste, com Sede em Caxias do Sul. São 90.718 km², ou seja, 
34\% do território do Estado do RS. A RGE faz parte do Grupo CPFL Energia, um dos maiores grupos privados do setor elétrico brasileiro (RGE, 2009a).

Quando da privatização, e ainda durante os dois primeiros anos de existência da companhia, a leitura dos medidores e a entrega de faturas eram realizadas por três empresas terceirizadas. Estes dois processos, além de terem um custo bastante elevado, apresentavam muitas falhas, gerando boa parte das reclamações por parte dos clientes. Dados do Departamento de Atendimento e Gestão Comercial da empresa indicam que, em janeiro de 2000, foram registradas 26.597 solicitações de segundas vias de faturas e 4.743 reclamações de faturas não entregues (RGE, 2000a).

Por meio de critérios estabelecidos pela ABRADEE - Associação Brasileira de Distribuidores de Energia Elétrica, as empresas do setor elétrico brasileiro têm indicadores que medem a satisfação dos clientes e a qualidade dos serviços prestados pelas distribuidoras. Um dos principais indicadores comerciais é o que mede a Qualidade do Faturamento. O QF, indicador de Qualidade de Faturamento, é a relação entre o número de faturas refaturadas a cada lote de 10.000 faturas emitidas. Dados do mesmo do relatório anual do Departamento de Atendimento e Gestão Comercial demonstram que em 1999 o QF era de 4,1. Este valor era acima do desejado, uma vez que havia uma meta estipulada para o QF de 2,5, o que comprometia a imagem da empresa junto ao mercado e junto aos seus clientes (RGE, 1999a).

Preocupada tanto com o volume de reclamações de faturas não entregues como com a qualidade do faturamento, e os custos relacionados a essas atividades, a RGE buscou reavaliar todo o seu processo de leitura e de entrega de faturas, que era terceirizado. O objetivo era melhorar a qualidade do serviço, obter ganhos com a mudança dos processos, reduzir os custos e melhorar a imagem da empresa. Tal avaliação resultou em uma decisão, a de verticalizar estas duas atividades, uma atitude pioneira no setor elétrico nacional, e que foi implementada no início de 2000.

De acordo com Berry (2001), os valores da inovação e da excelência estão fortemente vinculados. A inovação - modificando o que existe para algo melhor - é a principal ferramenta para se atingir a excelência. Ritzman e Krajewski (2004), por sua vez, afirmam que realizar o trabalho internamente (verticalização) pode significar melhor qualidade e maior pontualidade na entrega. Uma integração vertical acentuada geralmente é atrativa quando os volumes são elevados, porque volumes elevados permitem especialização de tarefas e maior eficiência. Ela também é atrativa se a empresa possui qualificações e encara os processos que está integrando como particularmente importantes para o seu sucesso futuro.

Dados de 2008 demonstram que os resultados apresentados por estes dois processos após a sua verticalização trouxeram melhorias consideráveis (RGE, 2008a). O índice de QF medido pela passou de 4,1, em 1999, para 1,18, em 2008. As solicitações de segundas vias, que em janeiro de 2000 somaram 26.597, foram reduzidas para uma média mensal de 557, em 2008; o número de 
reclamações de faturas não entregues passou de 4.743 em janeiro de 2000 para uma média mensal de 1.475. Outro dado extremamente importante é o fato de que, já no primeiro ano da verticalização, o custo médio destes dois processos foi reduzido para apenas um pouco mais de um terço do custo no período da terceirização.

Além disso, a Pesquisa ABRADEE (2009), de 2008, realizada pelo Instituto Vox Populi, mostra que o percentual de satisfação dos clientes da empresa em relação ao índice diretamente relacionado ao faturamento da conta de energia (contas sem erros, ou seja, com a leitura dos medidores e os cálculos corretos), passou de 72,1\%, em 1999, para 94,1\% em 2008. Já o índice que mede a satisfação em relação ao prazo entre o recebimento da fatura e o pagamento da conta, que está diretamente vinculado ao processo de entrega de faturas, passou de 75,1\%, em 1999, para 95,6\%, em 2008 (RGE, 2008b).

\section{Referencial Teórico}

\subsection{Definições e aspectos importantes em relação à qualidade em serviços}

Paladini (2007) comenta que a palavra "qualidade" apresenta características que implicam dificuldades de porte considerável para sua perfeita definição e não pode ser definida de qualquer modo. No que diz respeito à qualidade há pouca convergência em torno de sua definição (HUFF; FORNELL; ANDERSON, 1994). Como exemplo disso, é possível citar algumas definições de qualidade, as quais abordam diferentes enfoques. Qualidade é conformação a especificações (CROSBY, 1979), melhoria da conformação a especificações por meio da redução da incerteza e da variabilidade (DEMING, 1986), adequação ao uso (JURAN, 1989; JURAN; GODFREY, 1999), julgamento do cliente ou consumidor sobre a excelência global ou a superioridade de um produto ou de um serviço (ZEITHAML, 1988).

Fornell (1991) e Grönroos (2009) destacam que o mais importante é a definição do que seja qualidade sob a ótica do cliente. Por conseguinte, qualidade é conformação às especificações do cliente, e o que conta é o que o cliente percebe como qualidade (MILAN; BRENTANO; DE TONI, 2008). Sendo assim, na visão de Kotler e Keller (2006), a qualidade é a totalidade de aspectos e características de um produto e/ou serviço que proporcionam a satisfação de necessidades declaradas e implícitas.

No entanto, Bateson e Hoffman (2001) fazem uma diferenciação entre satisfação e qualidade e dizem que a satisfação do cliente é uma avaliação passageira, específica de uma transação, enquanto a qualidade do serviço é uma atitude formada por uma avaliação global de longo prazo de um desempenho. Ao avaliar o desempenho de um produto ou de um serviço, o cliente geralmente se utiliza da análise de seus principais atributos (OLIVER, 2010) e, neste sentido, a mensuração do 
nível de satisfação dos clientes serve como uma medida para se verificar o desempenho global da empresa em relação às expectativas dos clientes (ANDERSON; FORNELL; LEHMANN, 1992).

Grönroos (2009) defende que, falar sobre qualidade, sem melhor defini-la, sem esclarecer como é percebida pelos clientes e como pode ser melhorada, tem valor limitado. Na literatura sobre qualidade em serviços, nota-se que a qualidade de um serviço em particular é qualquer coisa que o cliente perceba que ela seja. Para Fitzsimmons e Fitzsimmons (2005), a qualidade em serviços começa com as pessoas, por meio do desenvolvimento de atitudes positivas entre todas as pessoas da organização. Para que a organização prospere, o pessoal de linha de frente precisa operar continuamente com alto nível de interesse e atenção pelas necessidades e expectativas dos clientes (ALBRECHT; ZEMKE, 2002).

Bateson e Hoffman (2001) ressaltam que as percepções de qualidade tendem a confiar em repetidas comparações da expectativa do cliente em relação a um determinado serviço com o seu real desempenho. Segundo Lovelock e Wright (2005), antes que os clientes comprem um serviço, eles possuem uma expectativa sobre a qualidade do serviço. Após a compra e o consumo, comparam sua qualidade esperada com o que realmente receberam. Se o desempenho ficar acima do nível de serviço desejado, será visto como de qualidade superior. Se ficar dentro do esperado, será considerado adequado, mas, se a qualidade real ficar abaixo do esperado, ocorrerá uma lacuna entre o desempenho de serviço e as expectativas do cliente.

Fitzsimmons e Fitzsimmons (2005) seguem na mesma linha de raciocínio e declaram que, em serviços, a avaliação da qualidade surge ao longo do processo de prestação. A satisfação do cliente com a qualidade do serviço pode ser definida pela comparação da percepção do serviço prestado com a expectativa do serviço desejado. Quando se excede a expectativa, ele é percebido como de qualidade excepcional. Quando, no entanto, não se atende às expectativas, a qualidade do serviço passa a ser inaceitável. Quando se confirmam as expectativas pela percepção do serviço, a qualidade é satisfatória. Essas expectativas derivam de várias fontes, entre elas a propaganda boca a boca, necessidades pessoais e experiências anteriores (OLIVER, 2010).

$\mathrm{Na}$ visão de Grönroos (2009), a qualidade do serviço tem duas dimensões: uma dimensão técnica, ou de resultado, e uma dimensão funcional, ou relacionada ao processo. O que os clientes recebem em suas interações com uma empresa é a dimensão da qualidade denominada qualidade técnica do resultado do processo de prestação de serviço. O cliente também é influenciado pelo modo como ele recebe o serviço e como experimenta o processo simultâneo de produção e de consumo (utilização do serviço). Essa é outra dimensão da qualidade, denominada qualidade funcional do processo.

Para Berry (2001), uma maneira das empresas controlarem seus destinos é controlando os processos que afetem diretamente as percepções de qualidade e de valor de seus clientes. Kotler e 
Keller (2006) dizem que uma das principais maneiras de uma empresa de serviços se diferenciarem de concorrentes é prestar serviços de alta qualidade. Já Ritzmann e Krajewski (2004) consideram que, em geral, o sucesso de uma empresa depende da precisão de suas percepções a respeito das expectativas do cliente e de sua habilidade para eliminar a lacuna entre as expectativas e as habilidades operacionais. Boa qualidade deve resultar em maiores lucros, enquanto que a má qualidade aumenta os custos para produzir o produto e/ou serviço.

Kotler e Armstrong (2003) defendem o mesmo ponto de vista e argumentam que um dos modos mais importantes de uma empresa se diferenciar de outras é executando consistentemente um serviço de qualidade superior. As empresas prestadoras de serviços devem garantir que, a cada execução, os clientes recebam consistentemente serviços de alta qualidade. Os autores ainda complementam que, a qualidade do relacionamento com os clientes e a lucratividade estão intimamente vinculados à qualidade dos serviços. Níveis mais altos de qualidade resultam em maior satisfação do cliente, ao mesmo tempo em que sustentam preços médios mais altos e, muitas vezes, a custos mais baixos (ganhos de escala).

\subsection{Falhas em serviços e a sua recuperação}

Conforme Bateson e Hoffman (2001) existem indícios consideráveis que mostram que se recuperar eficazmente de falhas de serviço contribui para as avaliações que os clientes fazem e por isso reforçam a importância de prestar um serviço de qualidade. Também é fato que serviços de má qualidade geram retrabalho e desperdício de recursos, onerando a organização. $\mathrm{Na}$ opinião dos autores, o controle eficaz das reclamações pode ter um impacto considerável no sentido de evitar que comentários negativos sobre a empresa se espalhem, melhorando o resultado final, e por isso devem merecer atenção especial por parte da gestão.

Lovelock e Wright (2005), ao fazerem uma análise sobre faturas, destacam que faturas imprecisas, ilegíveis ou incompletas oferecem uma excelente oportunidade para desapontar clientes que podem, até este momento, estar bastante satisfeitos com suas experiências. Faturas errôneas ou incompletas podem causar um maior impacto em clientes que já estejam insatisfeitos com a empresa por outros motivos, e que os clientes normalmente esperam que suas faturas sejam claras, informativas e otimizadas, de tal forma que não deixem dúvidas sobre como foi calculada (LOVELOCK; WIRTZ, 2004).

Todo esforço de qualidade na empresa tem custos associados, embora estes sejam pequenos se comparados com os custos de não se ter qualidade (GIANESI; CORRÊA, 2006). Nessa mesma perspectiva, Lovelock e Wright (2005) comentam que produtividade e qualidade devem ser vistas como duas faces da mesma moeda. A produtividade melhorada é essencial para manter os custos sob controle, mas não se pode reduzir indevidamente os níveis de serviço. Entretanto, investir na 
melhoria da qualidade sem entender o balanço entre os custos e incrementos na receita pode colocar em risco a rentabilidade da empresa.

Bateson e Hoffman (2001) e Hoffman e Bateson (2003) afirmam que as falhas ocorrem durante os vários "momentos da verdade", nas interações entre o cliente e a empresa, que ocorrem nos encontros de serviço. Os autores argumentam que os clientes entendem que as empresas às vezes falhem, mas igualmente esperam que sejam capazes de recuperar essas falhas. Apesar de todos os esforços das empresas, elas são inevitáveis. A própria natureza dos serviços acarreta a inevitabilidade de falhas, contudo, nem todos os clientes reclamam. Porém, se reclamam e a recuperação de serviço for bem-sucedida, costuma haver um paradoxo, pois os clientes avaliam mais positivamente o desempenho se acontece uma falha e o pessoal de contato soluciona o problema do que se o serviço tivesse sido bem-sucedido desde o começo.

Zeithaml e Bitner (2003), de igual modo, mencionam que se tem defendido a idéia de que clientes insatisfeitos, mas que fazem a experiência de uma excelente recuperação de falhas em serviços podem ficar ainda mais satisfeitos e mais dispostos a recompras do que aqueles que sempre estiveram satisfeitos. Porém, o paradoxo da recuperação é mais complexo do que parece. Antes de mais nada, é oneroso reparar erros e poderia parecer algo um tanto perigoso estimular falhas nos serviços. Conforme as autoras, pesquisas sugerem que o aumento da satisfação e da fidelidade de clientes somente ocorrerá quando a empresa atingir as mais altas taxas de recuperação de serviços, ou seja, ela precisa ser excepcional.

\subsection{Terceirização versus verticalização}

Com a crescente tendência de as empresas se focarem nas atividades que consideram centrais e terceirizarem atividades pouco relevantes, é freqüente que atividades de linha de frente sejam terceirizadas. Um erro freqüente é ter padrões de tratamento muito diferenciados para funcionários terceirizados. O cliente vai formar sua percepção de satisfação também levando em conta o momento da verdade em contato com o funcionário terceirizado, por isso, ele deve merecer exatamente o mesmo grau de preocupação, quanto ao recrutamento, treinamento, motivação, recompensa e outros aspectos (CORREAN; CAON, 2002).

Ritzmann e Krajewski (2004) defendem a tese de que se deve estudar cuidadosamente antes de optar pela terceirização ou verticalização. A análise financeira e do ponto de equilíbrio são bons pontos de partida. A adequação estratégica é outro ponto fundamental, e deve refletir tanto fatores quantitativos como qualitativos para que as análises sejam completas. Para os autores, uma empresa pode obter economias se possuir as qualificações e o volume de recursos para executar os processos a um custo menor. A alta administração precisa entender que, se a empresa terceiriza um processo 
crítico, ela pode perder o controle sobre essa área de atuação, e talvez a habilidade de realizar o trabalho internamente no futuro.

Na visão de Queiroz (1998), a qualidade é a principal preocupação quando se fala em terceirização, considerando-se que é dela que vai depender a continuidade da parceria. Da parte do contratante dos serviços deverá existir uma preocupação constante em auditar a qualidade do seu parceiro, sempre a comparando com os parâmetros pré-estabelecidos e que são esperados. Oliveira (1994) afirma que não é raro um contratante se deparar com problemas de qualidade ao passar para uma contratada parte de suas atividades. Mesmo que a contratante atente para os cuidados indicados, o risco continua sendo real.

Ritzmann e Krajewski (2004) afirmam que a terceirização é particularmente atrativa para as empresas que produzem volumes pequenos. Ela pode proporcionar melhor qualidade e economia de custos. Dois fatores que contribuem para essa tendência são a concorrência global e a tecnologia da informação. A primeira cria mais opções de fornecedores, já os avanços na tecnologia da informação tornam mais fácil a coordenação com esses fornecedores. Leiria, Souto e Saratt (1992) ressaltam que o ideal é aquele contratante que, não apenas levado pelo desejo momentâneo de baixar custos, desenvolve um plano global de terceirização na empresa, criando espaço para formar uma cultura de parceria.

A terceirização traz uma série de benefícios: redução de custos, diminuição de desperdícios, aumento da qualidade, sinergia entre atividades-fim, aumento da especialização, aumento do lucro, favorecimento da economia de mercado, otimização dos serviços, obtenção de efetividade no atendimento, melhoria da relação com sindicatos, redução dos níveis hierárquicos, agilidade nas decisões, aumento da produtividade e da competitividade, custos equilibrados do mercado de mãode-obra, reavaliação das necessidades, redução do quadro funcional, aumento da agilidade da organização, diminuição do passivo trabalhista e aumento dos empregos especializados (LEIRIA; SOUTO; SARATT, 1992; LEIRIA; SARATT, 1995; GIOSA, 1997; PAGNONCELLI, 1993).

Em contrapartida, os principais riscos e fatores restritivos à terceirização são: aumento do risco a ser administrado, dificuldades no aproveitamento de colaboradores treinados, demissões na fase inicial, mudanças na estrutura de poder, falta de parâmetros de preço nas contratações iniciais, custo das demissões, desgaste na relação com sindicatos, má escolha de parceiros, má administração do processo e aumento da dependência de terceiros, desconhecimento da alta administração, resistências e conservadorismo, falta de parâmetros de custos internos e o fato de que alguns gestores não querem a diminuição da estrutura sob o seu comando (LEIRIA; SARATT, 1995; GIOSA, 1997; PAGNONCELLI, 1993).

Oliveira (1994) ainda enfatiza que a terceirização pode resultar em outros problemas, tais como: utilização de mão-de-obra pouco habilitada para o trabalho e exploração de mão-de-obra por 
parte da firma contratada, taxas de administração cobradas incompatíveis com os custos operacionais e interferências da contratante na gestão da atividade terceirizada. $\mathrm{O}$ autor menciona que, quando as empresas se vêem na contingência de cortar despesas e de se fixar apenas naquelas operações que conhecem bem, as empresas terceirizam as atividades que podem ser terceirizadas, ou seja, as que sejam técnica e economicamente viáveis.

Segundo Pagnoncelli (2003), a redução de custos não deve ser a finalidade principal da terceirização. Todavia, embora o uso da terceirização tenha como objetivo focar a empresa na sua atividade-fim, na verdade, o mercado em geral busca a redução de custos. No curto prazo é o que realmente ocorre, mas no longo prazo o próprio futuro da empresa é ameaçado por diversos fatores: o custo de controle dos serviços terceirizados progressivamente torna-se maior, a queda de qualidade freqüentemente é relatada por clientes e perda de bons funcionários, devido à rotatividade da mão-de-obra dessas empresas (WIKIPÉDIA, 2009).

Alvarez (1996) destaca alguns cuidados que se deve ter com a terceirização: definir as atividades-fim, desenvolver um programa de conscientização de funcionários, avaliar os ganhos em qualidade e em eficiência, avaliar o processo de trabalho e os recursos dos terceiros, analisar aspectos contratuais e a qualificação do terceiro. Silva (1995) sustenta que, a terceirização, quando feita de forma eufórica, quando implementada inadequadamente, atribuindo a terceiros atividades que os funcionários podem fazer melhor e mais barato, representa um oneroso equívoco. Assim, tão logo a gestão tome conhecimento dos resultados, a terceirização sofrerá a primeira pressão para que seja revista ou mesmo descontinuada.

Cabe salientar que existem vários tipos de desperdícios e ineficiências dentro das organizações. Esses fatos levam o empresário a pensar que a terceirização é mais eficiente, barata e adequada para a empresa alcançar seus objetivos operacionais. Entretanto, mesmo naquelas tarefas passíveis de terceirização, o preço cobrado pode não corresponder às expectativas da parte contratante. Os erros que acontecem aqui igualmente acontecem lá. Muitas empresas experimentaram prejuízos fantásticos com a terceirização. Naquelas em que a cúpula tomou conhecimento dos resultados negativos, rapidamente iniciou-se o caminho de volta. Isso é o que se chama “pagar para ver”, ou seja, é o que reflete o preço do aprendizado (SILVA, 1995).

\section{Método de pesquisa}

\subsection{Caracterização do ambiente de pesquisa}

A empresa utilizada como ambiente de pesquisa é uma distribuidora de energia elétrica que atende a região norte-nordeste do Estado do RS. A companhia surgiu do processo de privatização de serviços públicos, ocorrida em outubro de 1997. Atualmente, atende a 262 municípios, que 
correspondem, de acordo com dados do IBGE (Instituto Brasileiro de Geografia e Estatística) de dezembro de 2007, a uma população de pouco mais de 3,7 milhões de habitantes. A RGE - Rio Grande Energia S/A. faz parte do Grupo CPFL Energia, um dos maiores grupos privados do setor elétrico brasileiro (RGE, 2009b).

A área de concessão da empresa abrange as Missões, Planalto Médio, Alto Uruguai, os Campos de Cima da Serra, toda a Serra Gaúcha e parte da Região Metropolitana. Agrupadas, estas regiões apresentam um dos melhores índices sociais e econômicos do Brasil, e é nelas que se localizam algumas das maiores concentrações industriais do RS, dentre elas, o Pólo MetalMecânico de Caxias do Sul, o Complexo Vitivinícola da Serra, o Pólo Automobilístico de Gravataí e uma parcela significativa da área produtiva do Complexo da Soja (RGE, 2006).

Para que os objetivos do estudo pudessem ser alcançados, optou-se por delimitar como objeto de análise dois processos: leitura e entrega de faturas de energia elétrica. A RGE foi pioneira na verticalização destes processos no final de 1999, quando situações externas elevaram os custos com estes dois processos que eram realizados de forma terceirizada. Também havia registro de um grande número de reclamações e os altos índices de retrabalho. É importante ressaltar que os serviços de distribuição de energia elétrica são extremamente regulados e fiscalizados pela ANEEL (Agência Nacional de Energia Elétrica), que exige que as empresas do setor prestem serviços com índices mínimos de qualidade.

\subsection{Objetivos da pesquisa e procedimentos adotados}

O objetivo geral da pesquisa é analisar os impactos resultantes da verticalização dos processos de leitura e de entrega de faturas de energia elétrica da empresa. Em acréscimo, foram estabelecidos quatro objetivos específicos: (i) descrever a migração dos processos em estudo, do modelo terceirizado para a situação atual, isto é, do modelo verticalizado; (ii) analisar os benefícios e os riscos, comparando-se os dois modelos; (iii) demonstrar os resultados obtidos com a verticalização dos processos analisados; e (iv) propor ações que possam contribuir para a melhoria dos processos e resultados obtidos.

Para a elaboração deste estudo, optou-se pela realização de um estudo de caso sobre uma atitude pioneira realizada por uma empresa de distribuição de energia elétrica localizada no Estado RS, que verticalizou dois processos importantes e que influenciam diretamente a relação entre a empresa e seus clientes, os processos de leitura e de entrega de faturas de energia, que, historicamente, sempre foram realizados por empresas terceirizadas. Yin (2004) salienta que o estudo de caso é caracterizado pelo estudo profundo e exaustivo de um ou de poucos objetos, de maneira que permita o seu amplo e detalhado conhecimento, tarefa praticamente impossível mediante os outros delineamentos existentes. 
Para tanto, foi realizada uma análise documental (VERGARA, 2006), verificando diversos documentos e relatórios da empresa, além da realização de entrevistas individuais em profundidade, com uma abordagem semi-estruturada (RIBEIRO; MILAN, 2004; MALHOTRA, 2006), com profissionais que participaram ou participam diretamente dos processos, de forma que fosse possível analisar os principais resultados e impactos gerados pela mudança. Portanto, foram entrevistados com cinco profissionais: o gerente e um dos supervisores dos processos em estudo, o responsável pelo controle dos indicadores destes processos e um dos colaboradores e o gestor da área de faturamento, que têm seu trabalho diretamente afetado pelas informações trazidas do campo e pelas entregas de faturas realizadas pelos agentes comerciais.

Em relação ao processo de análise e de interpretação dos dados, o principal desafio em investigações qualitativas está na utilização dos dados em sim e não na coleta dos mesmos (WOLCOTT, 1994), uma vez que, a partir de sua utilização, deveria haver a geração de conhecimento capaz de ampliar o entendimento sobre a realidade pesquisada, voltando-se para a compreensão do que pode ser feito e para que direção os dados podem conduzir (RIBEIRO; NEWMANN, 2003). Para tanto, foram seguidos pressupostos encontrados na literatura (WOLCOTT, 1994; RIBEIRO; MILAN, 2004; MALHOTRA, 2006), procedendo-se à análise de conteúdo (BARDIN, 2004).

\section{Desenvolvimento da pesquisa}

4.1 A migração dos processos: modelo terceirizado para verticalizado

No momento em que ocorreu a privatização da companhia, a leitura e a entrega das faturas era realizada por três empresas terceirizadas. Em 1998, a EBCT - Empresa Brasileira de Correios e Telégrafos se posicionou contra a prestação do serviço por parte daquelas três empresas, entendendo que este era um direito seu. A forma utilizada pela EBCT para isso foi uma ação de Mandado de Segurança, onde a sentença foi de que a RGE não poderia delegar a entrega à outra empresa que não a EBCT. No entanto, a sentença autorizava a empresa a entregar seus documentos por meio de quadro próprio de funcionários. A partir deste momento, a leitura continuou sendo realizada por empresas terceirizadas, porém, a entrega das faturas passou a ser realizada pelos Correios (EBCT).

As grandes alterações ocorridas no setor elétrico, a necessidade da empresa se tornar mais rentável, de reduzir os custos com a entrega, que aumentaram consideravelmente depois que esta atividade passou a ser realizada pela EBCT, e o fato dos Correios não realizarem entregas na zona rural, e a necessidade de elevar os índices de satisfação dos clientes, fez com que a empresa percebesse que só conseguiria atingir seus audaciosos objetivos se inovasse, revertendo o quadro 
histórico de terceirização dos processos de leitura e de entrega no setor elétrico no Brasil, absorvendo tais atividades.

O processo de verticalização foi estudado ao longo do ano de 1999, e acabou sendo parcialmente implantado no final daquele mesmo ano na Região Metropolitana. A implantação incluía um cronograma que envolvia recrutamento e admissão de pessoal (inicialmente foram admitidas as pessoas que já desempenhavam estas atividades através das empresas terceirizadas), contratação dos supervisores, compra de veículos (motocicletas), EPIs (equipamentos de proteção individual) e EPCs (equipamentos de proteção coletiva) e ainda equipamentos de informática. Todas estas ações foram concluídas em janeiro de 2000, quando o processo de verticalização foi efetivamente implementado.

Como os custos com estes processos tinham aumentado consideravelmente, a empresa tinha um grande interesse em implementar a verticalização com a maior brevidade possível, o que fez com que ela optasse, em um primeiro momento, em não elaborar um processo seletivo de pessoal mais detalhado, e sim aproveitar os profissionais que realizavam estas atividades como terceiros e que conheciam os processos. Essa decisão trouxe como conseqüência um alto turnover. Muitos destes profissionais tiveram de ser gradativamente substituídos por não atenderem às expectativas e o perfil desejado pela empresa.

Os dois primeiros meses da realização das atividades de forma verticalizada foram os mais turbulentos, principalmente por se tratar de um período de adaptação. Mesmo com a contratação dos funcionários, que eram terceirizados, e já realizavam as atividades, muitos deles não conheciam efetivamente o campo, houve muita dificuldade para a localização de determinadas ruas, bairros e linhas rurais que não possuem sinalização. Ao longo dos primeiros meses, ficou clara a necessidade de ações de treinamentos sobre o uso dos coletores de dados de leitura, questões de segurança, melhores práticas para atender aos clientes, trabalho em equipe e uso de EPIs, que foram mais intensamente realizados ao longo de 2001.

Com o intuito de facilitar a gestão dessas duas atividades, foram criadas treze Bases de Leitura e Entrega. Cada base possui um Encarregado que coordena as atividades diárias e a respectiva equipe de Leituristas e Entregadores. Foram designados dois Supervisores de Leitura e Entrega um para as regiões Serra e Metropolitana e outro para as regiões Noroeste, Planalto e Missões. Do processo de verticalização até o momento, várias alterações foram efetuadas. Em 2004, foi implantado o Ranking das Bases de Leitura e Entrega para estabelecer uma competição entre as Bases, ligadas ao desempenho de indicadores de segurança e comerciais, com premiação trimestral para os melhores desempenhos.

Também houve alterações no sentido de facilitar a execução das atividades. Uma delas foi a alteração dos cargos de Leiturista e Entregador, criando-se apenas o cargo de Agente Comercial, o 
que permite ao Encarregado da Base de Leitura e Entrega deslocar o funcionário para onde exista um maior acúmulo de serviço, facilitando os processos. O Agente Comercial desempenha atividades que antes competiam apenas ao Leiturista ou ao Entregador. Além disso, foram criadas algumas Sub-bases de Leitura e Entrega em alguns municípios estratégicos, com o objetivo de reduzir custos com deslocamento e o risco de acidentes.

\subsection{Benefícios e riscos da verticalização na visão da empresa}

Durante o ano de 1999 a RGE procurou fazer análises das principais implicações que ocorreriam diante da decisão de verticalizar os processos de leitura e de entrega de faturas. Por entender que estes dois processos impactam diretamente na relação da empresa com os seus clientes, a organização procurou analisar todas as variáveis envolvidas e desenvolver um projeto de implantação, buscando evitar que algumas falhas comprometessem sua imagem diante de seus clientes, que já vinha desgastada com as inúmeras ocorrências (falhas) que vinham sendo observadas com a terceirização destes processos.

Os estudos realizados (RGE, 1999b) demonstraram que a verticalização traria uma série de benefícios: redução dos custos operacionais, melhoria da imagem da empresa e da qualidade destes processos, diminuição do número de acidentes, de reclamações de faturas não entregues e de solicitações de segundas vias, aproximação RGE/cliente através do Leiturista e do Entregador (e mais adiante do Agente Comercial), possibilidade de agregar novas tarefas aos processos (recadastramentos, entrega de outros documentos, etc), padronização dos procedimentos, uma vez que o processo terceirizado era realizado por três empresas distintas, e entrega de faturas na área rural, atividade esta que não é realizada pela EBCT (em 1999, em torno de 140 mil faturas/mês).

A mudança nestes dois processos, também implicaria no fato da empresa ter de assumir alguns riscos, tais como: aumento do quadro funcional, aumento do risco de acidentes devido ao uso de motocicletas para fazer as entregas das faturas, investimento inicial elevado, admissão de pessoal com pouca qualificação, alto turnover, necessidade de readequação do calendário de faturamento, pois havia muita concentração de leituras em determinadas posições e ociosidade em outras, sendo que tal adequação implicaria em postergação da arrecadação (no faturamento ou no volume das receitas) até que os ajustes fossem concluídos.

Após a análise de todos os possíveis benefícios e riscos que estariam envolvidos em razão da alteração dos processos, a empresa decidiu por verticalizar os processos de leitura e de entrega das faturas de forma gradativa, entre o final de 1999 e início do ano de 2000. Mesmo diante do fato de ambos os processos envolverem um grande número de colaboradores e um alto volume de atividades, os resultados positivos logo começaram a surgir, principalmente com a redução significativa de custos, demonstrando claramente que a empresa tinha tomado a decisão mais 
acertada, ainda que o setor elétrico, como um todo, demonstrasse total resistência e descrédito em relação a esta inovação.

\subsection{Resultados obtidos com a verticalização dos processos}

O início das atividades dos processos de leitura e de entrega de faturas de forma verticalizada foi um grande desafio, principalmente em função do volume de atividades e do fato de que é necessário um determinado tempo para que um novo Agente Comercial conheça detalhadamente uma determinada região, possibilitando que as leituras e as entregas das faturas sejam efetuadas corretamente. No entanto, uma parte deste trabalho foi facilitado diante da atitude da empresa em procurar contratar para seu quadro funcional, colaboradores que já prestavam serviço para a RGE por meio das empresas terceirizadas.

Uma das atividades que resultava em um grande volume de retrabalho e um custo bastante elevado era a entrega de segundas vias, ainda mais porque os pedidos não são concentrados em uma única região, o que resulta em grandes deslocamentos. Outro aspecto relevante é a dificuldade em planejar esta parte do processo, uma vez que a demanda parte do próprio cliente, que muitas vezes extravia o documento. Entretanto, o elevado volume de solicitações que a empresa registrou em janeiro de 2000, 26.597 pedidos (RGE, 2000a), fez com que a empresa acreditasse que boa parte das solicitações era ocasionada pela falta de entrega da fatura original, mas não tinha meios, ou informações, para comprovar isto.

A Figura 1 mostra o número de solicitações de segundas vias recebido ao longo do ano de 2000 e demonstra a redução gradativa do número de pedidos registrados ao longo do primeiro ano de verticalização dos processos de leitura e de entrega das faturas. Os anos seguintes também registraram reduções gradativas no número de solicitações, resultados que foram sendo construídos à medida que os colaboradores conheciam mais detalhadamente os seus itinerários. Para se ter uma idéia, dados de 2005 até 2008 comprovam que a média de solicitações de segundas vias de fatura se mantém em menos de 600 pedidos mensais gerados através do RGE 24 Horas (RGE, 2008a), um sistema de atendimento direto aos clientes. 
Figura 1 - Número de solicitações de segundas vias de fatura em 2000

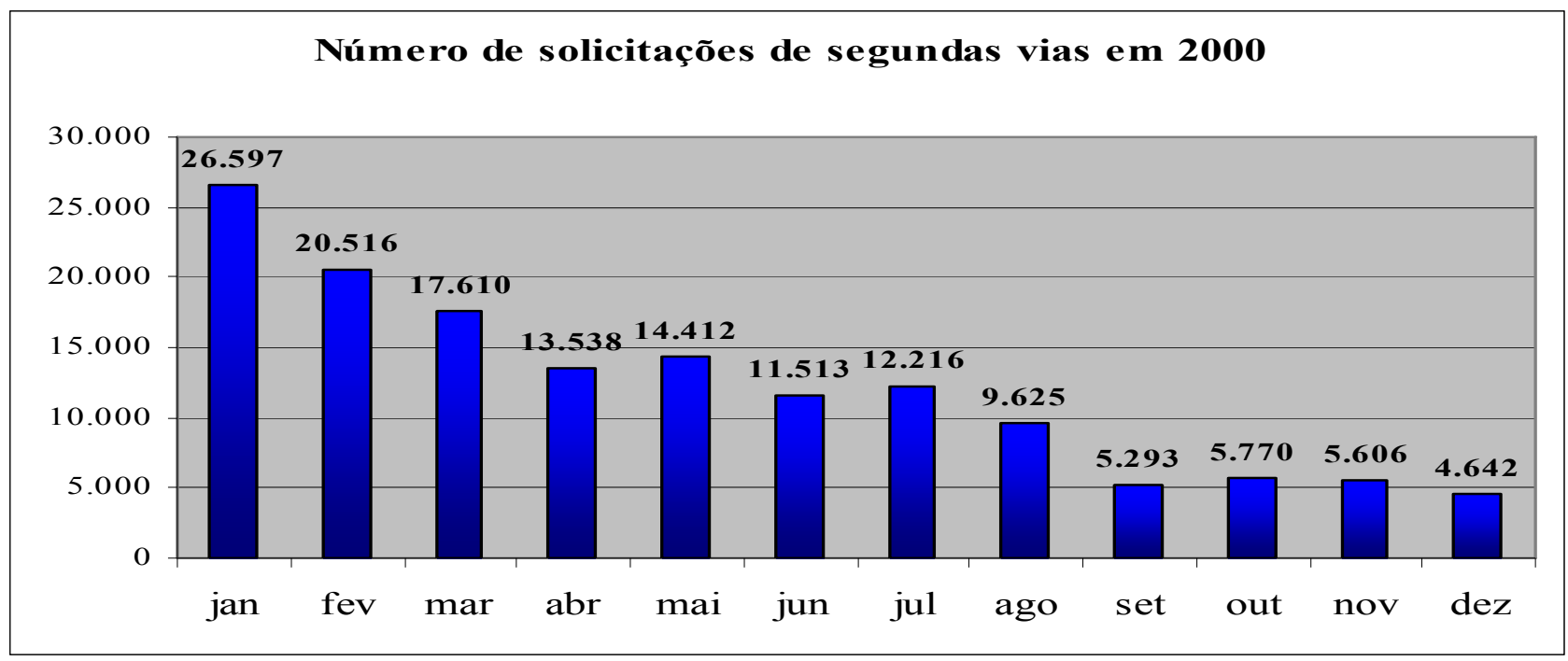

Fonte: Relatório de Solicitações de Segundas Vias (RGE, 2000b).

Outro dado bastante relevante se refere ao número de reclamações de faturas não entregues. Em janeiro de 2000 foram registradas 4.743 reclamações. Depois da verticalização, os dados comprovam uma melhora significativa neste número, mantendo, desde 2005, uma média mensal em torno de 1.500 reclamações. Do ano de 2005 em diante, a empresa passou a analisar mais detalhadamente cada reclamação, situação que não era possível com a terceirização, pois a empresa não tinha controle total sobre os processos e as informações. $\mathrm{O}$ acompanhamento possibilitou à empresa identificar que, em média, apenas $28 \%$ das reclamações são procedentes, ou seja, de faturas efetivamente não entregues (RGE, 2008a).

A melhoria nos processos de leitura e de entrega afetou positivamente o processo de faturamento. Em dezembro de 1999, a empresa registrou 79.596 anomalias de faturamento (RGE, 1999c). Uma anomalia pode ser gerada pelo sistema de faturamento basicamente por duas razões: consumos e valores a serem faturados acima da média do cliente, em relação aos parâmetros existentes no sistema ou, então, falhas no processo de leitura (erros ou ausência de leitura). Toda vez que o sistema gera uma anomalia, o faturamento só será processado depois que um usuário responsável aferir manualmente os dados para o correto faturamento.

Quanto maior o número de anomalias geradas pelo sistema, menor o tempo que cada responsável tem para analisar a unidade de consumo antes de processar o faturamento, o que aumenta o risco de falha humana. Após a verticalização, o número de anomalias geradas mensalmente pelo sistema sofreu uma redução. Em 2008 a média mensal foi de 38.555 anomalias. Este tipo de dado facilita o trabalho da Divisão de Faturamento, que dispõe de informações confiáveis trazidas do campo. Quanto maior a confiabilidade das leituras no campo, menor o número de releituras, reduzindo o retrabalho (RGE, 2008c). 
Um dos principais indicadores do Departamento de Atendimento e Gestão Comercial da empresa é o QF (Qualidade de Faturamento), que advém do IRC (Índice de Refaturamento de Contas). O QF é diretamente afetado pelos processos de leitura e de entrega de faturas. Quanto maior a qualidade destes processos, maior será a qualidade do faturamento, e menor o IRC. A Figura 2 comprova a evolução no indicador, desde a verticalização no início de 2000 até o final de 2008. De 2004 à 2008, a RGE vem mantendo sua condição de benchmarking como melhor índice de Qualidade de Faturamento do Brasil, resultado que só foi alcançado com a verticalização dos processos de leitura e de entrega de faturas (RGE, 2008d).

Figura 2 - Indicador de Qualidade de Faturamento (QF)

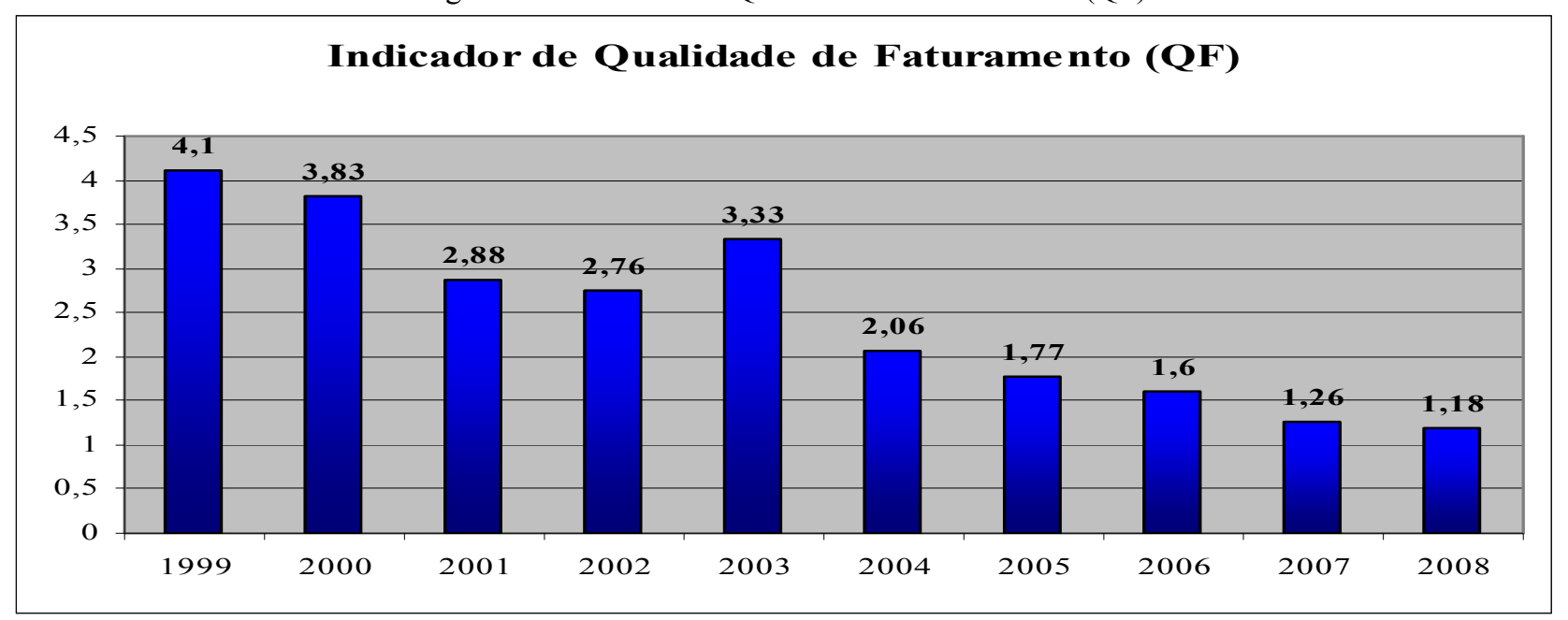

Fonte: Relatório de Qualidade de Faturamento (RGE, 2008d).

A empresa também está atenta aos índices de satisfação de seus clientes. A Pesquisa ABRADEE de 2008 demonstra que houve uma grande evolução nos índices de satisfação dos clientes da empresa em relação à conta de luz. Este índice resulta da satisfação em relação ao prazo entre o recebimento e o pagamento da conta (que avalia a entrega), e a conta de luz sem erros (que avalia a leitura). Em 2008, o índice médio no indicador Conta de Luz da pesquisa ficou em 95,5\%, muito superior aos 76,7\% registrados em 1999, e mais de dez pontos percentuais acima da média ABRADEE, que contempla as empresas do setor elétrico brasileiro, que possuem características equivalentes, segmentadas pelo número de clientes, que foi de 82,9\% em 2008 (RGE, 2008b).

Analisando separadamente o índice relacionado especificamente ao processo de entrega de faturas, tem-se uma evolução de 75,1\%, registrado em 1999, para 95,6\% de satisfação, em 2008, sendo que a Pesquisa ABRADEE (2009) neste mesmo ano demonstrou que no grupo de distribuidores em que a RGE se enquadra, a média registrada foi de $83 \%$. No índice relacionado ao processo de leitura, o resultado foi muito parecido. O índice da RGE passou de 72,1\%, em 1999, para $94,1 \%$, em 2008 , enquanto a média ficou em $80 \%$. Cabe ressaltar que houve uma melhora em 
mais de $10 \%$ nestes dois índices de satisfação já em 2000, primeiro ano em que os processos foram verticalizados.

Além da evidente melhoria na qualidade de ambos os processos, maior aproximação da empresa com os seus clientes e melhoria nos índices de satisfação, um dos principais fatores que faz com que a empresa mantenha esses processos de forma verticalizada, é o seu custo. Periodicamente, a companhia reavalia o seu custo-meta e o compara com os custos existentes no mercado, tanto pela EBCT quanto pelas empresas terceirizadas que executam estes serviços, de forma a assegurar que o custo praticado pela empresa continue menor do que o preço que seria pago em uma possível terceirização dos processos de leitura e entrega.

Dados do relatório de análise de custos de leitura e de entrega de faturas em relação ao mercado mostram que o custo efetivo da empresa, em 2005 , representou apenas $40 \%$ do que custaria para realizar estes dois processos caso a leitura fosse realizada por empresas terceirizadas e a entrega pela EBCT. De igual modo, foi analisado o custo da empresa em relação ao preço praticado por empresas terceirizadas (exceto EBCT) para realizar ambos os processos. O resultado demonstrado no relatório comprova que o custo da RGE, executando as atividades de forma verticalizada, é $20 \%$ menor em relação aos custos que a empresa teria caso optasse por, novamente, terceirizar estes dois processos (RGE, 2005).

\section{Discussão dos principais resultados}

O estudo de caso se propôs a relatar como foi a migração dos processos de leitura e de entrega de faturas de energia elétrica da empresa, que eram realizados de forma terceirizada e passaram a ser realizados de maneira verticalizada. Modificar dois processos importantes, que envolvem um volume diário de atividades extremamente elevado, um grande número de pessoas, e que impactam diretamente no faturamento da empresa, foi um desafio. É importante ressaltar que a empresa, em apenas três meses (tempo utilizado para realizar tal migração), passou a efetuar com pessoal próprio, mais de um milhão de leituras e de entregas de faturas ao mês, em 262 municípios gaúchos e que fazem parte de sua área de concessão.

Muitas adaptações tiveram de ser efetuadas durante e após a migração para que as atividades pudessem ser efetuadas de forma satisfatória, pois o planejamento nem sempre consegue prever todas as situações que mudanças deste tipo podem ocasionar. Além disso, foi necessário desenvolver as pessoas. Diferentemente do que ocorre em alguns processos, que podem ficar paralisados durante uma migração, os processos de leitura e de entrega não podem parar, e a margem tolerável para atrasos na execução dos processos é muito pequena. Ou seja, foi preciso realizar as atividades desde o início com assertividade, respeitando os prazos, procurando minimizar 
um certo nível de insegurança que existia em muitos membros da equipe diante do desafio de, em um período curto de tempo, passar a realizar os processos.

Outro aspecto abordado foi a análise prévia realizada pela empresa acerca dos benefícios e riscos atinentes à verticalização. Assim como os teóricos, que apontam pontos positivos e negativos tanto da verticalização quanto da terceirização, a RGE buscou identificar quais os principais benefícios e riscos que incorreria na verticalização. Os estudos realizados pela empresa indicavam que os resultados que poderiam ser obtidos com a mudança dos processos para um modelo verticalizado compensavam os riscos envolvidos e assumidos.

Por outro lado, o estudo também teve por objetivo demonstrar a evolução dos principais resultados obtidos pela empresa com a verticalização. Ficou evidente que houve uma melhora significativa em diversos aspectos: redução do número de solicitações de segundas vias, diminuição do número de reclamações de faturas de energia elétrica não entregues, melhoria na qualidade das leituras realizadas (redução dos erros e ausência de leituras), o que impacta diretamente no indicador de QF, bem como o aumento nos índices de satisfação dos clientes em relação aos processos de leitura e de entrega de faturas.

A verticalização facilitou o controle e o gerenciamento das informações oriundas do campo. Quando os processos eram terceirizados e três empresas executavam as atividades, era mais difícil padronizar e controlar os processos. Com a verticalização, a RGE pôde padronizar os processos, trabalhar com um único sistema de gerenciamento das informações e teve condições de identificar as situações onde existia um maior índice de retrabalho e de desperdício de recursos. Com a contratação de mão-de-obra própria, houve, ainda, uma maior facilidade na aproximação da RGE junto aos seus clientes.

Ao longo do trabalho, foram mencionados diversos autores que destacam a importância de prestar serviços de qualidade. Berry (2001) argumenta que, se a empresa tem a capacidade de controlar processos que afetam diretamente a percepção de qualidade e de valor para os seus clientes, ela conseguirá controlar seu próprio destino. Este era um grande objetivo que a RGE buscou atingir a partir do momento em que decidiu verticalizar os processos de leitura e de entrega das faturas, de forma que tivesse condições de prestar serviços de melhor qualidade, afetando positivamente a percepção dos clientes.

Prestar serviços de qualidade não significa que não ocorrerão falhas. Bateson e Hoffman (2001) e Hoffman e Bateson (2003) afirmam que a natureza dos serviços implica na inevitabilidade de falhas. Porém, percebe-se que a evolução dos indicadores e a melhoria da qualidade dos serviços prestados é um fato a partir da verticalização dos processos estudados. Tendo em vista a empresa possuir um maior controle sobre esses processos faz com que ela tenha condições de avaliar, 
identificar os erros e tomar as providências necessárias para corrigir suas falhas em um tempo menor ou até mesmo de forma preventiva.

Os clientes que reclamam querem que o seu problema seja solucionado com a maior brevidade possível, e a empresa só consegue atender a expectativa de seus clientes se tiver um controle detalhado sobre os seus processos. A possibilidade de identificar com segurança e precisão onde, quando e porque ocorreu a falha, facilita o trabalho da gestão de definir qual a melhor forma de corrigir o problema e buscar alternativas para que elas não ocorram novamente.

Para muitas empresas, a terceirização pode ser a melhor alternativa, no entanto, conforme destacado por autores como Ritzmann e Krajewski (2004) e Silva (1995), ela nem sempre é a melhor solução. Em processos que a empresa possui um grande volume de atividades, a qualificação e os recursos necessários para executar tais atividades internamente, ela pode ter um custo menor e melhores resultados do que com a terceirização. Este é especificamente o caso da RGE, que nos processos estudados possui um volume grande e constante de atividades, podendo, simultaneamente, a partir da verticalização, melhorar seus indicadores de qualidade e reduzir seus custos operacionais.

\section{Considerações finais}

Com o intuito de atender um dos objetivos do trabalho, de propor ações para potencializar os resultados, foi identificada a necessidade de aprimorar os sistemas de coletas de leituras de consumo, com o uso de novas tecnologias, como, por exemplo, o Palm top, que possui acoplado uma máquina fotográfica. Este equipamento poderia eliminar por completo a necessidade de realizar releituras, pois leituras duvidosas podem ser fotografadas e enviadas à equipe de faturamento. O uso da nova tecnologia também possibilita evidenciar as situações de falta de acesso, por meio de imagens e de registros. Atualmente, depois de um cliente questionar uma fatura emitida por estimativa, por falta de acesso, o Encarregado precisa se deslocar até o local para evidenciar a situação.

Esse sistema permitiria o envio de informações e até mesmo o faturamento e entrega da fatura em campo de forma on-line. Atualmente, o Agente Comercial precisa retornar à Base de Leitura para enviar as informações ao sistema de faturamento. Com as informações on-line, também poderia fotografar unidades consumidoras com suspeitas de irregularidade, o que facilitaria o trabalho de fiscalização, que teria condições de avaliar a necessidade de priorizar determinadas inspeções. Em acréscimo, o Agente Comercial poderia gerar ordens de serviço on-line para situações emergenciais, agilizando o atendimento de situações de risco.

Outro aspecto bastante importante que poderia ser aprimorado é o papel do Agente Comercial, que está focado somente em executar os processos de leitura e de entrega de faturas. 
No entanto, seu papel poderia ser muito mais importante junto aos clientes. Um novo desafio é preparar este colaborador para atuar como um verdadeiro agente comercial, capaz de esclarecer as dúvidas dos clientes, sejam elas relacionadas à fatura de energia ou qualquer outro procedimento ou serviço prestado pela empresa, o que requer da empresa o trabalho de capacitação e aperfeiçoamento do profissional para o desempenho destas atividades.

A transformação do perfil deste profissional possibilitará que a empresa tenha maiores ganhos, relacionados à redução de custos, com a diminuição do número de ligações no RGE 24 Horas, ou ainda com uma maior aproximação da empresa junto aos seus clientes, principalmente na área rural. Diferentemente do que ocorre na zona urbana onde muitas vezes os clientes nem percebem a presença do Agente Comercial, na zona rural, ele é a própria imagem da empresa. É com os Agentes que os clientes procuram esclarecer suas dúvidas, até porque a grande maioria deste público possui uma resistência natural em direcionar suas demandas ao RGE 24 Horas ou outros meios de comunicação, como a internet.

Por fim, conclui-se que tanto a verticalização quanto a terceirização podem trazer benefícios e riscos. Sendo assim, é imprescindível que cada organização, assim como fez a empresa analisada, busque a melhor alternativa para a sua realidade. A RGE, mesmo diante do fato de que dentro do setor elétrico nacional estes processos eram realizados de forma terceirizada, entendeu, após uma análise detalhada, que poderia inovar, melhorar os processos e reduzir seus custos com a sua verticalização. Os resultados obtidos até o momento só comprovam que a empresa fez a escolha certa, acumulando resultados positivos.

\begin{abstract}
The paper presents a case study about the vertical integration of the meter reading process and delivery of bills in an electricity distributor in southern Brazil. The work aims to describe the migration of processes involved in the outsourced model for a verticality model. The study also includes analysis of the risks and benefits of the both models. Another issue addressed is the results demonstration of the company in question, which were extremely significant since its deployment. The vertical integration brought a decrease in the number of complaints of undelivered bills, reducing the number of requests for duplicate bills, improved quality billing, lower costs and still a major improvement in levels of customer satisfaction regarding the services and meter reading and delivery bills. It is the relationship between the organization achievements with the existing theoretical framework on the subject, seeking to show that outsourcing is not always the best alternative.
\end{abstract}

Key-words: services process; vertical integration of processes; outsourcing.

\title{
Referências
}

ABRADEE - Associação Brasileira de Distribuidores de Energia Elétrica. Banco de dados. Disponível em: $<$ www.abradee.org.br>. Acesso em: 05 mai. 2009.

ALBRECHT, K. ; ZEMKE, R. Serviço ao cliente: a reinvenção da gestão do atendimento ao cliente. Rio de Janeiro: Campus, 2002.

ALVAREZ, M S. B. Terceirização: parceria e qualidade. Rio de Janeiro: Campus, 1996. 
ANDERSON, E. W.; FORNELL, C.; LEHMANN, D. R. Perceived quality, customer satisfaction, market share, and profitability. Working Paper, NQRC (National Quality Research Center): The University of Michigan, 1992.

BARDIN, L. Análise de conteúdo. 3. ed. Lisboa: Edições 70, 2004.

BATESON, J. E. G.; HOFFMAN, K. D. Marketing de serviços. 4. ed. Porto Alegre: Bookman, 2001.

BERRY, L. L. Descobrindo a essência do serviço: os novos geradores de sucesso sustentável nos negócios. Rio de Janeiro: Qualitymark, 2001.

CORRÊA, H. L.; CAON, M. Gestão de serviços: lucratividade por meio de operações e de satisfação dos clientes. São Paulo: Atlas, 2002.

CROSBY, P. B. Quality is free: the art of making quality certain. New York: New American Library, 1979.

DEMING, W. E. Out of the crisis. Cambridge: MIT Center for Advanced Engineering Study, 1986.

FITZSIMMONS, J. A.; FITZSIMMONS, M. Administração de serviços: operações, estratégia e tecnologia de informação. 4. ed. Porto Alegre: Bookman, 2005.

FORNELL, C. National and corporate customer satisfaction indexes. A presentation at the World Quality Day. Amsterdam: World Trade Center, 1991.

GIANESI, I. G. N.; CORRÊA, H. L. Administração estratégica de serviços: operações para a satisfação do cliente. São Paulo: Atlas, 2006.

GIOSA, L. A. Terceirização: uma abordagem estratégica. 5. ed. São Paulo: Pioneira, 1997.

GRÖNROOS, C. Marketing: gerenciamento e serviços. 3. ed. Rio de Janeiro: Elsevier, 2009.

HOFFMAN, K. D.; BATESON, J. E. G. Princípios de marketing de serviços: conceitos, estratégias e casos. São Paulo: Thomson Learning, 2003.

HUFF, L.; FORNELL, C.; ANDERSON, E. W. Quality and productivity: contradictory and complementary. Working Paper, NQRC (National Quality Research Center): The University of Michigan, 1994.

JURAN, J. M. Juran on leadership for quality. New York: Free Press, 1989.

JURAN, J. M.; GODFREY, A. Blanton. Juran's quality handbook. $5^{\text {th }}$ edition. New York: McGraw-Hill, 1999.

KOTLER, P.; ARMSTRONG, G. Princípios de marketing. 9. ed. São Paulo: Prentice Hall, 2003.

KOTLER, P.; KELLER, K. L. Administração de marketing. 12. ed. São Paulo: Prentice Hall, 2006.

LEIRIA, J. S.; SARATT, N. D. Terceirização: uma alternativa de flexibilidade empresarial. 8. ed. São Paulo: Gente, 1995.

LEIRIA, J. S; SOUTO, C. F.; SARATT, N. D. Terceirização passo a passo: o caminho para a administração pública e privada. Porto Alegre: Sagra - DC Luzzatto, 1992.

LOVELOCK, C. H.; WIRTZ, J. Services marketing: people, technology, strategy. $5^{\text {th }}$ edition. Upper Saddle River, New Jersey: Pearson Prentice Hall, 2004.

LOVELOCK, C. H.; WRIGHT, L. Serviços: marketing e gestão. São Paulo: Saraiva, 2005.

MALHOTRA, N. K. Pesquisa de marketing: uma orientação aplicada. 4. ed. Porto Alegre: Bookman, 2006.

MILAN, G.S.; BRENTANO, J.; DE TONI, D. A qualidade percebida dos serviços prestados por uma agência de comunicação e a satisfação de clientes: um estudo exploratório. Revista Brasileira de Gestão de Negócios, v.10, n.26, p. 17-26, 2008.

OLIVEIRA, M. A. Terceirização: estruturas e processos em xeque nas empresas. São Paulo: Nobel, 1994. 
OLIVER, R. L. Satisfaction: a behavioral perspective on the consumer. $2^{\text {nd }}$ edition. New York: M.E. Sharp Inc., 2010.

PAGNONCELLI, D. Terceirização \& parceirização: estratégias para o sucesso empresarial. Rio de Janeiro: s.n., 1993.

PALADINI, E. P. Gestão da qualidade: teoria e práticas. 2.ed. São Paulo: Atlas, 2007.

QUEIROZ, C.A.R.S. Manual da terceirização: como encontrar os caminhos para a competitividade, com flexibilidade empresarial e atendimento do mercado, ganhando a concorrência e satisfazendo os anseios e interesses dos consumidores. 10. ed. São Paulo: STS, 1998.

RGE - Rio Grande Energia S/A. Relatório Anual do Departamento de Atendimento e Gestão Comercial (1999). Caxias do Sul: RGE, 1999a.

1999b.

Relatório de Análise de Viabilidade de Leitura e Entrega Verticalizada (1999). Caxias do Sul: RGE,

Relatório de Anomalias de Faturamento (1999). Caxias do Sul: RGE, 1999c.

2000a.

Relatório Anual do Departamento de Atendimento e Gestão Comercial (2000). Caxias do Sul: RGE,

Relatório de Solicitações de Segundas Vias (2000). Caxias do Sul: RGE, $2000 \mathrm{~b}$.

. Relatório de Análise de Custos dos Processos de Leitura e Entrega (2005). Caxias do Sul: RGE, 2005.

. Relatório RGE XVII SENDI - Seminário Nacional de Distribuição de Energia Elétrica (2006). Caxias do Sul: RGE, 2006.

$2008 \mathrm{a}$.

Relatório Anual do Departamento de Atendimento e Gestão Comercial (2008). Caxias do Sul: RGE,

Pesquisa ABRAdeE 2008. Caxias do Sul: RGE, 2008b.

Relatório de Anomalias de Faturamento (2008). Caxias do Sul: RGE, 2008c.

Relatório de Qualidade de Faturamento (2008). Caxias do Sul: RGE, 2008d.

Quem somos. Disponível em: www.rge-rs.com.br. Acessado em: 05 mai. 2009a.

Números. Disponível em: <www.rge-rs.com.br>. Acessado em: 13 jul. 2009.

RIBEIRO, J. L. D.; MILAN, G. S. Planejando e conduzindo entrevistas individuais. In: RIBEIRO, J. L. D.; MILAN, G.S. (eds.). Entrevistas individuais: teoria e aplicações. Porto Alegre: FEENG/UFRGS, 2004. cap.1, p. 9-22.

RIBEIRO, J. L. D.; NEWMANN, C. S. R. Planejando a condução de grupos focados. In: Grupos focados: teoria e aplicações. RIBEIRO, J. L. D. (ed.). Porto Alegre: FEENG/UFRGS, 2003. cap.1, p. 9-23.

RITZMAN, L. P.; KRAJEWSKI, L. J. Administração da produção e operações. São Paulo: Prentice Hall, 2004.

SILVA, F. G. Terceirização: paradoxos e contradições. São Paulo: Francisco Gomes, 1995.

VERGARA, S. C. Projetos e relatórios de pesquisa em administração. 7.ed. São Paulo: Atlas, 2006.

YIN, R. K. Estudo de caso. 3. ed. Porto Alegre: Bookman, 2004.

WIKIPÉDIA. Terceirização. Disponível em:<http: www.wikipedia.org.br>. Acessado em: 06 ago. 2009.

WOLCOOT, H. F. Transforming qualitative data: description, analysis, and interpretation. Thousand Oaks: Sage Publication, 1994. 
ZEITHAML, V. A. Consumer perceptions of price, quality and value: a means-end model of synthesis of evidence. Journal of Marketing, v. 52, n. 3, p. 2-22, 1988.

ZEITHAML, V. A.; BITNER, M. J. Marketing de serviços: a empresa em foco no cliente. 2.ed. Porto Alegre: Bookman, 2003.

\section{Agradecimentos:}

Agradecemos à RGE - Rio Grande Energia S/A. pela disponibilidade em servir como ambiente de estudo e a todos os seus gestores e colaborados que nos auxiliaram no processo de coleta de dados.

\section{Nome completo: Gabriel Sperandio Milan}

Filiação institucional: UCS - Universidade de Caxias do Sul

Departamento: Administração

Função ou cargo ocupado: Professor e Pesquisador

Endereço Completo para correspondência (bairro, cidade, estado, país e CEP): Rua: Francisco Getúlio Vargas, 1130 - Bloco F - Bairro: Petrópolis - Caxias do Sul - RS - Brasil - CEP: 95070560

Telefones para contato: (54) 3218.21.00

e-mail:gsmilan@ucs.br

Nome completo: Patrícia Fritzen Theisen

Filiação institucional: UCS - Universidade de Caxias do Sul

Função ou cargo que ocupa: Aluna do curso de Pós-Graduação - Especialização em Administração Estratégica de Serviços

Endereço Completo para correspondência (bairro, cidade, estado, país e CEP): Rua: Francisco Getúlio Vargas, 1130 - Bloco F - Bairro: Petrópolis - Caxias do Sul - RS - Brasil - CEP: 95070560

Telefones para contato: (54) 3218.21.00

e-mail:patitheisen@gmail.com

Enviado em: 10/02/2010

Aprovado em:04/03/2011 